\title{
Effect of Powdered Achantina Fulica Species Snail Shell on Wound Morphometry of Wistar Rats
}

\author{
Peter D. Okoh ${ }^{1 *}$, John N. Paul ${ }^{2}$, Esanye T. Ofoeyeno ${ }^{2}$ \\ ${ }^{1}$ Department of Surgery, Faculty of Clinical Sciences, College of Health Sciences, University of Port Harcourt, Nigeria \\ ${ }^{2}$ Department of Anatomy, Faculty of Basic Medical Sciences, College of Health Sciences, University of Port Harcourt, Nigeria
}

DOI: $10.36348 /$ sjm.2020.v05i03.005 $\quad$ | Received: 19.02 .2020 | Accepted: 07.03.2020 | Published: 18.03 .2020

*Corresponding author: Peter D. Okoh

Abstract

Background: Wound healing is the process of repair that follows injury to the skin and other soft tissues. It is a natural restorative response to tissues injury. In the primitive years a lot of substances were considered to be medicinal and were used to enhance wound size contraction and closure. Similarly, the Iwere people of Delta State, Nigeria are known for using Achantina fulica species shell for wound healing although there is no known empirical study showing its ability to enhance wound contraction. Thus, this study was aimed at assessing the wound healing effect of powdered snail shell of Achantina fulica species on the wound sizes of rat. Materials and Methods: Eight wistar rats were used and grouped into experimental and control groups. Paravertebral round wound of $2 \mathrm{~cm}$ were made on the skin of each rat under light chloroform anesthesia. The wounds were treated with powdered snail shell and $0.9 \%$ normal saline for the experimental and control group respectively. Wound sizes were measured everyday using a meter rule before redressing. Results and Discussions: Day 1, 2, 3, showed percentage reduction of $100 \%, 99 \% 92.5 \%$ for those of the experimental group while $99 \%, 94 \%$ and $90 \%$ for those of the control group. On day 4, the percentage reduction was $72 \%$ for the experimental while $86 \%$ for the control group. This was the first outstanding wound size reduction observed in rats dressed with powdered snail shell. The wound size reduction continued from day 5- 12 with a percentage reduction of $61.5 \%, 50 \%$, $40 \%, 34 \%, 26.5 \%, 24 \%, 15 \%, 9 \%$ for the experimental group while that of the control group was $86 \%, 76.5 \%$, $65 \%$, $63.7 \% 57.5 \%, 55 \%, 51.5 \%, 47.5 \%, 42.5 \%$. Conclusion: The wounds treated with powered snail shell by day 13 was completely healed while those on $0.9 \%$ normal saline took 21 days to heal. It suggests that the powdered Achantina fulica shell promoted the wound size contraction which further led to a rapid healing and wound closure earlier than the control in the study. It could be inferred that this Achantina fulica shell powder could be refined and used as an alternative substance for wound healing.

Keywords: Snail shell, Wound size, Healing, Achantina Ftulica.

Copyright @ 2020: This is an open-access article distributed under the terms of the Creative Commons Attribution license which permits unrestricted use, distribution, and reproduction in any medium for non-commercial use (NonCommercial, or CC-BY-NC) provided the original author and source are credited.

\section{INTRODUCTION}

The human body protects itself from the external environment by an outer layer of skin and subcutaneous tissue (fatty tissue) [1]. The skin is our shield from the outside world and means of interacting with it. Skin consists of two layers: Epidermis and Dermis.' The outer portion, epidermis is composed of epithelium cells (20-30 cells deep) that protect the body from bacterial invasion. The inner portion, dermis gives skin its strength and vitality. The subcutaneous tissue lying under the skin functions as pad by absorbing pressure and prevents injury to body organs and structures. The skin is subjected to various insult and injuries and as such wounds are common place from childhood to old age and are necessary for surgical entry.
The term wound refers to trauma to any of the tissues of the body especially that caused by physical means and with interruption of continuity and also refers to a surgical incision [2]. According to the immediate effect produced, wounds are classified into four varieties namely incised, punctured, lacerated, and contused. Incised wounds are clean cuts made using a sharp instrument making the tissues divide without any damage to surrounding parts [2]. Punctured wounds are wounds produced by sharp pointed objects with the opening relatively small compared to the depth into underlying tissues. Lacerated wounds are torn or jagged wounds caused by blunt trauma while contused wounds are mechanical injury usually caused by a blow resulting in hemorrhage beneath unbroken skin [2]. 
Wound healing is the process of repair that follows injury to the skin and other soft tissues. It is a natural restorative response to tissues injury. Cells on the surface of the skin are constantly being replaced by regeneration from below with the top layers sloughing off thus repair of an epithelial wound is merely a scaling up of this normal process. Healing is the interaction of a complex cascade of cellular events that generates resurfacing, reconstitution and restoration of the tensile strength of injured skin [3].

Although healing is a systematic process, traditionally explained in terms of 3 classic phases: inflammation, proliferation and maturation [3], in actuality, the entire process is much more complicated as cellular event that lead to scar formation occurs in tandem. This process is fundamentally the same in all wounds with marked quantitative variations, which is dependent on the amount of tissue destruction and to a certain extent on the presence or absence of an infection.

When wound is inflicted on an individual, nature attempts to cover the wound to prevent infection by the growth and migration of epithelial cells (the first layer of skin). This natural method is slow and explains why infection of wound is common. Wound management by physicians assists nature by carrying out occlusive dressing on wound. Occlusive dressing has made physicians aware of the possibility of improving and controlling the healing process [4]. Some of the effects of occlusive dressings run counter to many decades of traditional surgical training and wound care $^{[4]}$ using different dressing agents and one of such substances is powdered snail shell (The shell of the Achantina fulica species) used by the Iwere people of Delta state of Southern Nigeria. This form of occlusive dressing is believed to hasten the wound healing process.

\section{WOUND HEALING}

The clinical history of the treatment of acute and chronic wounds can also trace its origins to ancient Egypt. The Ebers Papyrus, circa 1500 BC, details the use of lint, animal grease, and honey as topical treatments for wounds. The lint provided its natural absorbency, the animal grease provided a barrier to environmental pathogens, and the honey served as an antibiotic agent [5]. The Brugsch Papyrus, circa 1200 $\mathrm{BC}$, stated that the Egyptians believed that making sure a person's wound stayed closed would help their own spirit not be invaded by external evil spirits [4-7].

There are basic signs that indicate a wound is healing which include: swelling, stiffness, tenderness, discoloration, skin tightness, scabbing, itching and scar formation [5]. The advantages of occlussive dressings are speedy healing of acute wound, enhanced healing of chronic non-healing wounds, reduction of wound pain and tenderness [4].

\section{PROFILE OF THE SNAIL AND ITS SHELL}

The name snail applies to most members of the mollusk class Gastropod that have coiled shells. The giant Africa snail, Achantina fulica, is a very large snail; adults are usually around 7 to $8 \mathrm{~cm}$ tall and can reach $20 \mathrm{~cm}$ or more in length. It is a diverse group of large land snails most prevalent in Africa [12].

The shell of the Achantina fulica snail has a rounded conical shape being twice as high as it is broad with length ranging from $80 \mathrm{~mm}$ to $220 \mathrm{~mm}$ [12]. The shell is generally brown in color with irregular darker streaks running transversely across the whorls [3]. The shell has 6.5 whorls that are usually very pronounced or rounded. The shell is quite thick and robust [12].

The shell consists of three layers namely the periostracum, ostracum and hipostracum [4]. The periostracum is the outer layer. It is an organic layer made up of several layer of conchioline, which contains pigments that make up the color of the shell. The ostracum also known, as the prismatic layer is the underlying layer is a strong, calcium rich layer that normally do not contains pigment and it is white in color. The inner layer called the hipostracum is attached to the prismatic layer with a very thin layer of conchioline and also contains calcium carbonate crystals that are oriented parallel to the shell surface [14].

The thickness of the shell depends on the species, the age of the snail and the environmental conditions such as the calcium concentrations of the water [14]. The shell is usually made up of nacre, calcium carbonate and conchioline [15-17].

Nacre: Nacre also known as mother of pearl is an organic mixture of the outer horny conchioline, followed by an intermediate layer of calcium carbonate especially aragonite in the form of platy crystals (hexagonal platelets) arranged in continuous parallel lamina separated by sheets of organic matrix $[15,16]$. It is secreted by the epithelial cells of the mantle tissue and deposited onto the inner surface of the animal's shell continually thus forming an iridescent nacreous layer. Its function is to smoothen the shell itself and act as a defense against parasitic organisms and damaging detritus $[15,16]$.

Conchioline: Conchioline (conchin) is a scleroprotein secreted by a mollusk outer epithelium (the mantle). Scleroproteins also known as fibrous protein are usually used to construct connective tissues and are responsible for skin elasticity. This protein is a part of a matrix of organic macromolecule that assembles together and forms the microenvironment where crystals nucleates can grow. This organic matrix holds and binds the crystals of aragonite that gives the snail shell its stiffness. Conchioline serve as a relatively flexible crack-deflecting matrix of mineral aggregate 
particles; its strength and the strong bonding give the finished material (nacre) an impressive level of toughness [15].

\section{Calcium Carbonate}

The shell of the snail is primarily made up of calcium carbonate hence the need for calcium in their diet and watery environment to produce a strong shell [16]. The ions that are necessary to form calcium carbonate are also secreted by the mantle tissue and nucleate with conchioline. Lack of calcium carbonate can cause thin, cracked or perforated shells [16].

\section{Uses of Snail Shell}

Research work in this area is very limited, not specific and falls short of explanation but the very basic use of the giant African land snail is for food. As food, the giant African land snail serves as a source of protein. Studies have shown that the giant African land snail has been introduced to other countries such as is seen in Singapore during the world war for its use as food because it is a potential source of protein. Again, some West African countries use it as a source of iron and protein. It is marketed fresh or smoked dried [8]. As food additive, it is used in some soymilk products as a source of dietary calcium [18].

The giant Africa land snail is also used in native medicines in the West Africa. The species was introduced into Mauritius and other islands in the Indian oceans as well as Hawaiian Islands of Maui for its medicinal remedies. ${ }^{[18]}$ Researchers have identified a compound known as acharan sulphate produced by snail which has an anti-tumor activity. Calcium carbonate is widely used medicinally as an inexpensive calcium supplement antacids and phosphate binder [17].

Apart from powdered snail shell, many herbs are also useful in wound healing. In animal studies of skin inflammation, both topical and oral aloe vera have proven beneficial in decreasing inflammation and promoting cellular repair $[9,20]$. Topical aloe vera has facilitated wound healing in controlled human research, as well [21].

Some studies have been done in the past on wound healing using other substances to demonstrate the effects on contraction and wound closure [8-11, 13, $15,16,19,21-26]$.

\section{AIM OF THE STUDY}

This study was aimed at assessing the wound healing effect of powdered snail shell of Achantina fulica species on the wound size of rat.

\section{MATERIALS AND METHOD Preparation of Powdered Snail Shell}

The content of an adult giant Africa land snail (Achatina Fulica sp.) was removed from its shell, washed in a running water to rid impurities, afterwards the shell was put in an open flame to burn until it was brittle. Then the brittle shell was crushed to smooth powdery form using a laboratory mortar and finally stored in a dry container.

\section{Acclimatization of experimental rats}

Eight wistar rats of both sexes weighing between $150 \mathrm{~g}$ and $200 \mathrm{~g}$ where purchased from University of Port Harcourt animal farm and brought to histology laboratory of the College of Health Sciences for acclimatization in a period of two weeks. This was done to facilitate a better adaptation of these animals to their new environment. The rats were fed with guinea feed and given adequate water throughout the period of acclimatization and afterwards. After the expiration of the acclimatization period, the rats were grouped into two: a control group and an experimental group.

\section{Wound Infliction}

Each rat was placed on the dissecting board and under light chloroform anesthesia; the hair on each rat back at the lower lumber region was shaven. With the aid of colour marker a $2 \mathrm{~cm}$ length and breadth was drawn on the skin of the rats. Then using a forcep, the skin of the marked area was raised and cutoff using a dissecting blade. The time of inflictions and initial length and breadth was noted. This was repeated for all the other rats in both the experimental and control group. Shortly after wound infliction, wound dressing commenced.

\section{Wound Dressing}

For the control group, the wound was cleaned with normal saline and left exposed. Whereas for the experimental group, after cleaning the wound, the powdered snail shell of Achatina Fulica was applied using forceps, then covered with a sterile gauze and plaster.

\section{Wound Morphometry (Measurement)}

Dressing of the wound was done every day. The percentage increase or reduction in the size of the wound was measured using a standard measuring rule every day before redressing it. The whole process of dressing and measurement continued till the wound was fully healed. The duration it took before complete healing and closure was noted. The average reduction and percentage reduction of the wound size was calculated thus:

Actual wound size: $2 \mathrm{~cm}$

Average Reduction: $\frac{\text { Sum of post wound sizes }}{4}$

$$
\% \text { Reduction }=\frac{\text { Average } \text { Reduction }}{2} \times 100
$$

\section{Precautions}

The animals were acclimatized for a period of two weeks before commencement of study. All standard protocols of bench works were strictly followed, animals were well fed and kept in a 
conducive environment as required. The wounds were of the same size (length and breadth) and the powdered snail shell kept dry in an air tight container.

\section{RESULTS}

Table-1: Experimental group results

\begin{tabular}{|l|l|l|l|l|l|l|l|}
\hline $\begin{array}{l}\text { No. of } \\
\text { days }\end{array}$ & $\begin{array}{l}\text { Rat } \\
(\mathbf{c m})\end{array}$ & $\begin{array}{l}\text { Rat 2 } \\
(\mathbf{c m})\end{array}$ & $\begin{array}{l}\text { Rat } \\
(\mathbf{c m})\end{array}$ & $\begin{array}{l}\text { Rat } \\
(\mathbf{c m})\end{array}$ & $\begin{array}{l}\text { Sum of } \\
\text { new sizes }\end{array}$ & $\begin{array}{l}\text { Average } \\
\text { reduction }\end{array}$ & $\begin{array}{l}\% \\
\text { Reduction }\end{array}$ \\
\hline 1 & 2.00 & 2.00 & 2.00 & 2.00 & 8.00 & 2.00 & $100 \%$ \\
\hline 2 & 1.90 & 2.00 & 2.00 & 2.00 & 7.90 & 1.98 & $99 \%$ \\
\hline 3 & 1.90 & 1.80 & 2.00 & 2.00 & 7.40 & 1.85 & $92.5 \%$ \\
\hline 4 & 1.50 & 1.20 & 1.60 & 1.50 & 5.80 & 1.45 & $71.5 \%$ \\
\hline 5 & 1.30 & 0.90 & 1.40 & 1.30 & 4.90 & 1.23 & $61.5 \%$ \\
\hline 6 & 1.00 & 0.80 & 1.20 & 1.00 & 4.00 & 1.00 & $50 \%$ \\
\hline 7. & 0.80 & 0.60 & 1.00 & 0.80 & 3.20 & 0.80 & $40 \%$ \\
\hline 8. & 0.70 & 0.50 & 0.80 & 0.70 & 2.70 & 0.68 & $34 \%$ \\
\hline 9. & 0.50 & 0.40 & 0.60 & 0.60 & 2.10 & 0.53 & $26.5 \%$ \\
\hline 10. & 0.50 & 0.30 & 0.60 & 0.50 & 1.90 & 0.48 & $24 \%$ \\
\hline 11 & 0.30 & 0.20 & 0.40 & 0.30 & 1.20 & 0.30 & $15 \%$ \\
\hline 12 & 0.30 & .00 & 0.30 & 0.10 & 0.70 & 0.18 & $9 \%$ \\
\hline 13 & 0.00 & 0.00 & 0.00 & 0.00 & 0.00 & 0.00 & $0.00 \%$ \\
\hline
\end{tabular}

Table-2: Control group results

\begin{tabular}{|l|l|l|l|l|l|l|l|}
\hline $\begin{array}{l}\text { No. of } \\
\text { days }\end{array}$ & $\begin{array}{l}\text { Rat 1 } \\
(\mathbf{c m})\end{array}$ & $\begin{array}{l}\text { Rat 2 } \\
(\mathbf{c m})\end{array}$ & $\begin{array}{l}\text { Rat } \\
(\mathbf{c m})\end{array}$ & $\begin{array}{l}\text { Rat } \\
(\mathbf{c m})\end{array}$ & $\begin{array}{l}\text { Sum } \begin{array}{c}\text { of } \\
\text { new sizes }\end{array} \\
\text { Average } \\
\text { reduction }\end{array}$ & $\begin{array}{l}\text { \% } \\
\text { Reduction }\end{array}$ \\
\hline 1 & 2.00 & 2.00 & 1.90 & 2.00 & 7.90 & 1.98 & $99 \%$ \\
\hline 3 & 1.90 & 1.90 & 1.80 & 1.90 & 7.50 & 1.88 & $94 \%$ \\
\hline 4 & 1.80 & 1.80 & 1.80 & 1.80 & 7.20 & 1.80 & $90 \%$ \\
\hline 5 & 1.70 & 1.80 & 1.70 & 1.70 & 6.90 & 1.73 & $86 \%$ \\
\hline 6 & 1.50 & 1.60 & 1.50 & 1.50 & 6.10 & 1.53 & $76.5 \%$ \\
\hline 7. & 1.30 & 1.40 & 1.30 & 1.20 & 5.10 & 1.28 & $65 \%$ \\
\hline 8 & 1.30 & 1.30 & 1.30 & 1.20 & 5.10 & 1.28 & $63.75 \%$ \\
\hline 9. & 1.20 & 1.10 & 1.20 & 1.10 & 4.60 & 1.15 & $57.5 \%$ \\
\hline 10. & 1.10 & 1.10 & 1.10 & 1.10 & 4.40 & 1.10 & $55 \%$ \\
\hline 11 & 1.10 & 1.00 & 1,00 & 1.00 & 4.10 & 1.03 & $15.5 \%$ \\
\hline 12 & 0.90 & 0.90 & 1.00 & 1.00 & 3.80 & 0.95 & $47.5 \%$ \\
\hline 13 & 0.80 & 0.90 & 0.80 & 0.90 & 3.40 & 0.85 & $42.5 \%$ \\
\hline 14 & 0.70 & 0.80 & 0.70 & 0.89 & 3.00 & 0.75 & 37.5 \\
\hline 15 & 0.70 & 0.70 & 0.70 & 0.70 & 2.80 & 0.70 & $35 \%$ \\
\hline 16 & 0.60 & 0.50 & 0.50 & 0.70 & 2.30 & 0.58 & $29 \%$ \\
\hline 17 & 0.50 & 0.40 & 0.40 & 0.50 & 1.80 & 0.45 & $22.5 \%$ \\
\hline 18 & 0.40 & 0.30 & 0.30 & 0.40 & 1.40 & 0.35 & $17.5 \%$ \\
\hline 19 & 0.30 & 0.20 & 0.30 & 0.40 & 1.20 & 0.30 & $15 \%$ \\
\hline 20 & 0.20 & 0.10 & 0.20 & 0.03 & 0.80 & 0.20 & $10 \%$ \\
\hline 21 & 0.10 & 0.10 & 0.10 & 0.20 & 0.50 & 0.12 & $6 \%$ \\
\hline 22 & 0.10 & 0.00 & 0.10 & 0.10 & 0.30 & 0.80 & $4 \%$ \\
\hline & 0.00 & 0.00 & 0.00 & 0.00 & 0.00 & 0.00 & 0.00 \\
\hline
\end{tabular}

\section{DISCUSSION}

The wound morphometry in the experimental group was compared with that of the control, and the following were observed: On days 1, 2 and 3, the wounds dressed with powdered snail shell had a percentage reduction of $00 \%, 99 \%$ and $92.5 \%$ while those dressed with $0.9 \%$ normal saline (control group) had a percentage reduction of $99 \%, 94 \%$ and $90 \%$. These observations showed that powdered snail shell had little or no effect on the initial phase (inflammatory phase) of wound healing. This agrees with the findings of Fonder et al., [18] and other authors [13, 15, 16].

On day 4, however, the percentage reduction of the experimental group was $72 \%$ while that of the control group was $86 \%$. This was the first outstanding change observed on the wound sizes of the rats dressed with powdered snail shell. It showed that powdered snail shell contributed to the proliferative phase of 
wound healing. This result was consistent with previous reports on wound healing by other authors [8-11].

This change in wound size continued on days $5-10$ with a percentage reduction to $61.5 \%, 50 \%, 40 \%$, $34 \%, 26.5 \%, 24 \%$ for the experimental group and $76.5 \%, 65 \%, 63.75 \%, 57.5 \%, 55 \%, 51.5 \%$ for the control group respectively. On days 11-13, the percentage reductions for the experimental were $15 \%$, $9 \%, 0 \%$ whereas those of the control were $47.5 \%$, $42.5 \%, 37.5 \%$. This continual rapid change in wound size observed in experimental group brought the complete closure of the wound to day 13 while for the control healing was on till day 22. There was a significant wound size percentage reduction difference in the wound closure days between the experimental and control groups with the experimental group showing a shorter period before total wound closure. This again corroborates the reports of previous authors in their studies [21-26].

This suggests that the powdered snail shell probably stimulated the factors involved in wound healing thus speeding the healing process. This could be attributed to the presence of conchioline and calcium carbonate in the shell of snail (Achantina fulica) which may have aided granulation tissue formation.

\section{CONCLUSION}

The wounds treated with powered snail shell by day 13 was completely healed while those on $0.9 \%$ normal saline took 21 days to heal. It suggests that the powdered Achantina fulica shell promoted the wound size contraction which further led to a rapid healing and wound closure earlier than the control in the study. It could be inferred that this Achantina fulica shell could be refined and used as an alternative substance for wound healing.

\section{ACKNOWLEDGEMENTS}

We sincerely appreciate the entire management and staff of the Department of Surgery, Faculty of Clinical Sciences, College of Health Sciences, University of Port Harcourt, Nigeria and Department of Anatomy, University of Port Harcourt.

Conflict of Interest: We write to state that there is no conflict of interest.

Source of Funding: Self-funding.

\section{AUTHOR'S CONTRIBUTION}

We write to state that all authors have contributed significantly and that all authors are in agreement with the contents of the manuscript. 'Author A' (Peter D. Okoh) designed the study and protocol, wrote the first draft of the manuscript; reviewed the design, protocol; 'Authors B' (John N. Paul) examined the intellectual content of the manuscript, 'Authors C' (Esanye T. Ofoeyeno) did the analysis of the study and literature search. All authors read and approved the final manuscript.

\section{REFERENCES}

1. Ger, R., Evans, J. T., \& Oddsen, R. (1996). A clinical trial of wound closure by constant tension approximation. The American journal of surgery, 171(3), 331-334.

2. John, H. D. (2001). Stedman's concise medical dictionary for the Health professions, 4th edition, Lippincott Williams and Wilkins publication.

3. Helfman, T., Ovington, L., \& Falanga, V. (1994). Occlusive dressings and wound healing. Clinics in dermatology, 12(1), 121-127.

4. William, H., Eagistein, P. M., \& Mertz, V. F. (1991). Clinical and Experimental approaches to Dermal and Epidermal Repair; Normal and Chronic Wounds, Edition, Wiley-liss mc, 262-263.

5. Breslow, R. A., Hallfrisch, J., Guy, D. G., Crawley, B., \& Goldberg, A. P. (1993). The importance of dietary protein in healing pressure ulcers. Journal of the American Geriatrics Society, 41(4), 357-362.

6. Gilchrist B. The Microbiology of Wounds. In: Altmeyer P., Hoffmann K., el Gammal S., Hutchinson J. (eds) Wound Healing and Skin Physiology. Springer, Berlin, Heidelberg. 1995.

7. Hutchinson, J. J., \& Lawrence, J. C. (1991). Wound infection under occlusive dressings. Journal of Hospital Infection, 17(2), 8394.

8. Edibamode, E. I., Paul, C. W., \& Obude, O. A. (2015). A Comparative Study of the Wound Healing Role of Lycopersicon esculentum Fruit and Gentamicin Ointment on Male Wistar Rats. Scholars Academic Journal Bioscience, 3(2A):143-149

9. Farahpour, M. R. (2019). Medicinal Plants in Wound Healing. In Wound Healing-Current Perspectives. IntechOpen.

10. Shedoeva, A., Leavesley, D., Upton, Z., \& Fan, C. (2019). Wound Healing and the Use of Medicinal Plants. Evidence-Based Complementary and Alternative Medicine, 2019.

11. Paul, C. W., Ezon-Ebidor, E. I., \& Paul, J. N. (2017). Effect of whole snake tomatoe (trichosanthes cucumerina) on wound healing using wistar rat. EJPMR, 4(11):57-61.

12. Mead, A. R. (1961). The giant African snail. University of Chicago Press.

13. Edibamode, E. I., Olotu, E. J., Allison, T. A., \& Otobo, E. O. (2014). Effect of $28 \%$ Concentration of Trichosanthes cucumerina Linn. (Snake Tomato) Seed on Wound Healing Using Male Wistar Rats. Scholars Journal Applied Medical Science, 2(2D):804-811.

14. Keawjam, R. S., \& Upatham, E. S. (1990). Shell morphology, reproductive anatomy and genetic patterns of three species of apple snails of the 
genus Pomacea in Thailand. Journal of Medical and Applied Malacology, 2, 45-57.

15. Innocent, E. E. E., Wokpeogu, P. C., Sudor, W. B., \& Nwolim, P. J. The Effect Of Ethanolic Seed Extract Of Solanum Lycopersicum On Wound Healing. EJPMR, 5(1):356-361.

16. Wilson, O. C. (2015). IE Alternative woundhealing effects of coconut oil extract using adult wistar rats. International journal of medicine and health profession research, 2(2), 43-50.

17. Mayer, G. (2005). Rigid biological systems as models for synthetic composites. Science, 310(5751), 1144-1147.

18. Fonder, M. A., Lazarus, G. S., Cowan, D. A., Aronson-Cook, B., Kohli, A. R., \& Mamelak, A. J. (2008). Treating the chronic wound: A practical approach to the care of nonhealing wounds and wound care dressings. Journal of the American Academy of Dermatology, 58(2), 185-206.

19. Davis, R. H., Stewart, G. J., \& Bregman, P. J. (1992). Aloe vera and the inflamed synovial pouch model. Journal of the American Podiatric Medical Association, 82(3), 140-148.

20. Leitner, M. G., Russo, J. M., \& Byrne, M. E. (1989). Wound healing oral and topical activity of Aloe vera. Journal American Podiatric Medical Association, 79(5):55-62.

21. Shelton, R. M. (1991). Aloe vera: its chemical and therapeutic properties. International journal of dermatology, 30(10), 679-683.
22. Morisset, R., Cote, N. G., Panisset, J. C., Jemni, L., Camirand, P., \& Brodeur, A. (1987). Evaluation of the healing activity of hydrocotyle tincture in the treatment of wounds. Phytotherapy research, 1(3), 117-121.

23. Kartnig, T. (1986). Clinical applications of Centella Asiatic (L) Urb. In Herbs, Spices, and Medicinal Plants: Recent Advances in Botany, Horticulture, and Pharmacology, 3. Craker, L. E., \& Simon, J. E. (eds), Phoenix, AZ: Oryx Press, 145-173.

24. Bossé, J. P., Papillon, J., Frenette, G., Dansereau, J., Cadotte, M., \& Le, J. L. (1979). Clinical study of a new antikeloid agent. Annals of plastic surgery, 3(1), 13-21.

25. Shukla, A., Rasik, A. M., \& Dhawan, B. N. (1999). Asiaticoside- induced elevation of antioxidant levels in healing wounds. Phytotherapy Research: An International Journal Devoted to Pharmacological and Toxicological Evaluation of Natural Product Derivatives, 13(1), 50-54.

26. Shukla, A., Rasik, A. M., Jain, G. K., Shankar, R., Kulshrestha, D. K., \& Dhawan, B. N. (1999). In vitro and in vivo wound healing activity of asiaticoside isolated from Centella asiatica. Journal of ethnopharmacology, 65(1), 111. 